\title{
Acer triflorum: A maple species that serves as a resource for nervonic acid and that has an ultralow erucic acid content
}

\author{
Yajing $\mathrm{SU}^{1}\left(\mathbb{0}\right.$, Wenxin $\mathrm{XUE}^{1}$, Bingyu JIA ${ }^{1}$, Jiangtao $\mathrm{CHU}^{1}$, Libin $\mathrm{WANG}^{2}$, Zhen FENG ${ }^{1 \star}$, Xiaoyan $\mathrm{YU}^{1 \star}$
}

\begin{abstract}
In this experiment, pulse NMR and gas chromatography were used to determine the seed oil content and fatty acid composition of Acer triflorum. In addition, the morphological characteristics of samaras and seeds were measured by conventional methods. The results showed that the average oil content of the tested seeds was $33.44 \pm 0.098 \%$ and revealed the presence of 16 fatty acids, of which six constituted $93.57 \%$ of the total oil cocent: linoleic acid, oleic acid, docosadienoic acid, peanutenedioic acid, palmitic acid and nervonic acid. In particular, the erucic acid content was less than $1 \%$. Fifteen morphological indexes were measured and used as a reference for breeding Acer triflorum. This is the first study to investigate the seed oil content and fatty acid composition of Acer triflorum.
\end{abstract}

Keywords: Acer triflorum; oil content; erucic acid; nervonic acid; woody oil.

Practical Application: The ultralow erucic acid content of Acer triflorum seed oil is be conducive to the development of this species as a source of healthy and high-quality edible oil.

\section{Introduction}

Members of the Acer genus are major landscape tree species, timber tree species and shelterbelt tree species in China. These species are important to ecology, society, and the economy; are used in medical treatment, health care and the landscape; and have broad application prospects. There are more than 150 species of Acer, the most popular being Acer palmatum, Acer truncatum, etc. Acer truncatum is a popular woody oil-producing tree species. The seed oil of this species is considered a high-quality, high-grade, healthy edible oil, and its unique nervonic acid plays an important role in brain health. Nervonic acid (C24:1 $\Delta 15$, cis-15-tetracosenoic acid, NA) is a very long-chain fatty acid whose name originated from the original discovery in mammalian nerve tissues. Nervonic acid, which is known as a "double-effect miracle substance," can repair nerve fibers, remove dead fibers and promote the regeneration of nerve cells (Hu et al., 2017) and also enhance neurodevelopment in premature infants. Since it is difficult for human body to produce nervonic acid, it is very important to take it in vitro. To date, only Lunaria annua has been considered as a niche crop for future development (Chen et al., 2017) due to the limited availability of the other plants, which cannot satisfy the market demand for nervonic acid-contained oil. Therefore, it is necessary to explore other resources containing nervonic acid to meet the market demand.

In addition to Acer truncatum, Acer monomaxim, Acer buergerianum Miq., Acer palmatum and Acer negundo have also been studied for their seed oil content and fatty acid composition. The results showed that the seed oil content of Acer truncatum was the highest (43.86\%); the five main fatty acids in Acer seed oil are oleic acid, linoleic acid, palmitic acid, arachidonic acid, nervonic acid and erucic acid; the mass fraction of nervonic acid was between $4.30 \%$ and $9.41 \%$, and the mass fraction of erucic acid was between $12.75 \%$ and $17.79 \%$ (Li et al, 2018). The content of erucic acid, a kind of 22-carbon long-chain fatty acid, in these five Acer species is high. Consumption of food rich in erucic acid has been found to have negative effects on health and erucic acid has been classified a natural toxicant (Abbott et al., 2003). According to previous studies, long-term exposure to high concentrations of erucic acid can damage heart tissue (Kramer et al., 1992; Bremer \& Norum, 1982). Although this has never been reported in humans, it has been reported in experimental and production animals such as rats, pigs and chickens (Sissener et al., 2018). Several reports have suggested that the consumption of mustard/rapeseed oil with more than $7 \%$ erucic acid can cause myocardial lipidosis and fibrosis in animals, thus making it undesirable for human consumption (Schiefer et al., 1978; Mersel et al., 1979; Chien et al., 1983). Furthermore, regulations in Canada state that in cooking oil, margarine, salad oil, simulated dairy products, shortening or other foods that resemble margarine or shortening, the erucic acid and cetoleic acid content must not exceed $5 \%$ of the total fatty acid content (Government of Canada, 1978). Therefore, it is highly important to identify maples that are sources of nervonic acid but also have a low erucic acid content. Acer triflorum, a member of the Aceraceae family, is a deciduous tree species that is distributed mainly in southeastern Heilongjiang, Jilin, Liaoning and other provinces of China as well as in Korea (Flora of China Editorial Committee, 2008). This species has an attractive red autumn leaf color and is the best tree species for growing autumn-color forests in Northeast China. In addition, 
this species produces ample amounts of nectar. Research on the ornamental value and cultivation techniques of Acer triflorum is currently very popular, but other aspects are lacking. Owing to its large seed size, we hypothesized that this species may contain a high oil content and high nervonic acid content, so we studied the oil content and fatty acid composition of its seeds.

\section{Materials and methods}

\subsection{Plant materials}

Samaras of Acer triflorum were collected from Xinbin Manchu Autonomous County, Liaoning Province (N125.03979 E41.73371), in October 2018. The selected plants that produced the samaras were mature and free of disease, and they were strongly growing. The samaras were naturally dried in the shade, and their seeds were dried at $103 \pm 2{ }^{\circ} \mathrm{C}$ to determine the oil and fatty acid contents.

\subsection{Morphological index determination}

The following 15 morphological indexes of the samaras and seeds of Acer triflorum were measured with straightedge, protractor, Vernier caliper and analytical balance: fruit length, fruit thickness, wing length, wing width, fruit/wing ratio, open angle, connection angle, inserted tail length, seed length, seed width, seed thickness, 100-seed weight, 100-fruit weight, kernel percentage and moisture content (Li et al., 2011).

\subsection{Oil content}

Oil extraction was determined using Soxhlet extraction according to the China National Standards (GB 5009.6-2016). Approximately $5 \mathrm{~g}$ of kernels were crushed into a powder and then subjected to Soxhlet extracter using petroleum ether (boiling point $30-60^{\circ} \mathrm{C}$ ) as the solvent at $60^{\circ} \mathrm{C}$ for $8-10 \mathrm{~h}$. After solvent evaporation, the flask containing fat was dried at $105^{\circ} \mathrm{C}$, cooled in a desiccator, and reweighed (Liang et al., 2019).

\subsection{Fatty acid determination}

Fatty acid composition was determined by gas chromatograph (GC). the specific method referenced Liang et al. (2019). The fatty acid methyl esters (FAMEs) profiles obtained for each accession were determined using an Agilent 7890A (Agilent, Palo Alto, CA, USA) gas chromatography (GC) equipped with a flame ionization detector (FID) using 17:0 FAME as an internal standard. The DB-23 capillary column (length $30 \mathrm{~m}$, inner diameter $0.32 \mathrm{~mm}$, film thickness $0.25 \mu \mathrm{m}$ ) was used in this detection. The injector and detector temperatures were $230{ }^{\circ} \mathrm{C}$ and $280{ }^{\circ} \mathrm{C}$, respectively. Oven temperature was held at $180{ }^{\circ} \mathrm{C}$ for $5 \mathrm{~min}$, with a rise of $3{ }^{\circ} \mathrm{C} \cdot \mathrm{min}^{-1}$ to $230{ }^{\circ} \mathrm{C}$. The carrier gas (helium) was delivered using a flow rate of $1.0 \mathrm{~mL} \bullet \mathrm{min}^{-1}$ and $1 \mu \mathrm{L}$ samples were injected manually using a split injection mode. Fatty acid methyl ester peaks were identified by comparing their retention time with those of known standards run under the same conditions. The data were reported as the mean \pm standard deviation.

\section{Results and discussion}

\subsection{Morphological characteristics}

The morphological characteristics of samaras and seeds are very important to the breeding of Acer triflorum. The statistical data of 15 quantitative characteristics are shown in Table 1. Among these characteristics, the open angle presented the largest coefficient of variation-0.470. The 100 -seed weight, kernel percentage and moisture content were $4.17 \pm 0.111 \mathrm{~g}, 17.1 \pm 0.208 \%$ and $7.29 \pm 0.209 \%$, respectively, which are important in terms of the production of Acer triflorum seed oil in the future.

Table 1. Morphological characteristics of the ssamaras and seeds of Acer triflorum.

\begin{tabular}{|c|c|c|c|c|c|}
\hline Morphological characteristics & Mean & Min & Max & Standard deviation & $\begin{array}{l}\text { Coefficient of } \\
\text { variation }\end{array}$ \\
\hline Fruit length (mm) & 10.27 & 7.00 & 14.00 & 1.365 & 0.133 \\
\hline Wing length (mm) & 36.19 & 22.00 & 45.00 & 6.868 & 0.189 \\
\hline Wing width $(\mathrm{mm})$ & 13.68 & 9.00 & 19.00 & 1.775 & 0.129 \\
\hline Open angle $\left(^{\circ}\right)$ & 30.47 & 5.00 & 70.00 & 14.330 & 0.470 \\
\hline Connection angle $\left({ }^{\circ}\right)$ & 32.91 & 15.00 & 50.00 & 7.539 & 0.229 \\
\hline Seed length $(\mathrm{mm})$ & 6.34 & 5.22 & 7.07 & 0.392 & 0.062 \\
\hline Seed width $(\mathrm{mm})$ & 4.31 & 3.34 & 5.28 & 0.478 & 0.111 \\
\hline Seed thickness (mm) & 3.73 & 2.65 & 4.96 & 0.423 & 0.113 \\
\hline 100-fruit weight (g) & 24.37 & 23.87 & 24.72 & 0.364 & 0.015 \\
\hline Kernel percentage (\%) & 17.10 & 16.84 & 17.35 & 0.208 & 0.012 \\
\hline Moisture content (\%) & 7.29 & 6.89 & 7.64 & 0.309 & 0.042 \\
\hline
\end{tabular}




\subsection{Oil content}

The oil content is a crucial index of whether a crop can be used for production, and the higher the oil yield is, the lower the cost of production (Kumar \& Sharma, 2011). The results showed that the seed oil content of Acer triflorum was $33.44 \pm 0.098 \%$. This content was slightly higher than that of Acer truncatum (28.57\%) reported by Liang et al. (2019) and lower than that of Acer truncatum (47.60\%) reported by Liang et al. (2019), which meant that the oil production capability of Acer triflorum was similar to that of Acer truncatum.

\subsection{Fatty acid composition}

In this study, Acer triflorum seed oil was found comprise mainly 16 fatty acids (Table 2). Among them, linoleic acid $(\mathrm{C} 18: 2,44.01 \pm 0.289 \%)$, oleic acid $(\mathrm{C} 18: 1,20.64 \pm 0.621 \%)$, docosadienoic acid (C22:2, $12.68 \pm 0.381 \%)$, peanutenedioic acid (C20:2, $6.78 \pm 0.162 \%)$, palmitic acid (C16:0, $4.96 \pm 0.210 \%)$ and nervonic acid (C24:1, $4.50 \pm 0.144 \%)$ were constituted the greatest proportion, accounting for $93.57 \%$. Notably, the erucic acid content was $0.74 \pm 0.049 \%$, which was much lower than that of Acer truncatum (16.49\%) (Liang et al., 2019).

Linoleic acid, a major compound found among the fatty acids of Acer triflorum, has been thoroughly demonstrated to lower blood cholesterol and low-density lipoprotein (LDL) cholesterol concentrations, particularly when it replaces common saturated fatty acids (Calder, 2015; Rabionet et al., 2014). Oleic acid is a monounsaturated fatty acid, and high oleic acid contents in edible oil can reduce harmful LDLs in human blood, prevent arteriosclerosis (Chang \& Huang, 1998), avoid the production of harmful trans-fatty acids (Nelson, 1998) and prolong the shelf-life of vegetable oil products; in addition, oleic acid has a high oxidation stability and yields few oxidation products

Table 2. Fatty acid composition of Acer triflorum.

\begin{tabular}{lcc}
\hline & Fatty acid & Composition (\%) \\
\hline C16:0 & Palmitic acid & $4.96 \pm 0.210$ \\
C16:1 & Palmitoleic acid & $0.06 \pm 0.005$ \\
C17:0 & Heptadecanoic acid & $0.14 \pm 0.005$ \\
C17:1 & Heptadecenoic acid & $0.07 \pm 0.005$ \\
C18:0 & Stearic acid & $2.12 \pm 0.090$ \\
C18:1 & Oleic acid & $20.64 \pm 0.621$ \\
C18:2 & Linoleic acid & $44.01 \pm 0.289$ \\
C18:3 & Linolenic acid & $1.99 \pm 0.066$ \\
C20:0 & Arachidic acid & $0.33 \pm 0.005$ \\
C20:1 & Peanutoic acid & $0.28 \pm 0.047$ \\
C20:2 & Peanutenedioic acid & $6.78 \pm 0.162$ \\
C22:0 & Behenic acid & $0.33 \pm 0.014$ \\
C22:1 & Erucic acid & $0.74 \pm 0.049$ \\
C22:2 & Docosadienoic acid & $12.68 \pm 0.381$ \\
C24:0 & Tetracosanoic acid & $0.32 \pm 0.012$ \\
C24:1 & Nervonic acid & $4.50 \pm 0.144$ \\
\hline
\end{tabular}

(Ge et al., 2015). Docosadienoic acid can promote health and is beneficial to the human body (Meesapyodsuk et al., 2018). The content of nervonic acid in Acer triflorum was $4.50 \pm 0.144 \%$, which was a little lower than that of Acer truncatum (6.10 $\pm 0.63 \%)$ (Liang et al., 2019), but it is enough to be a maple species that serves as a resource for nervonic acid. Especially, the content of erucic acid was less than $1 \%$, which was in agreement with the foreign edible oil standard.

\section{Conclusion}

The seed oil content of Acer triflorum was $33.44 \pm 0.098 \%$ and revealed the presence of 16 fatty acids, of which nervonic acid was $4.50 \pm 0.144 \%$ and erucic acid was $0.74 \pm 0.049 \%$. The ultralow erucic acid content solves the problem of too high erucic acid content in the seed oil of Acer truncatum. Acer triflorum is currently more commonly used as an ornamental species and for greening, but as an economic oil tree species, there is a lack of investment and research. Notably, Acer triflorum has great development potential. However, several aspects require further in-depth research, such as the production of Acer triflorum seed oil, the industrialization of high-quality species, the development and utilization of medicine and the resultant medicinal value, and the exploration of high-yield cultivation technology.

\section{References}

Abbott, P., Baines, J., Fox, P., Graf, L., Kelly, L., Stanley, G., \& Tomaska, L. (2003). Review of the regulations for contaminants and natural toxicants. Food Control, 14(6), 383-389. http://dx.doi.org/10.1016/ S0956-7135(03)00040-9.

Bremer, J., \& Norum, K. R. (1982). Metabolism of very long-chain monounsaturated fatty acids $(22: 1)$ and the adaptation to their presence in the diet. Journal of Lipid Research, 23(2), 243-256. PMid:7042878.

Calder, P. C. (2015). Functional roles of fatty acids and their effects on human health South. Journal of parenteral and enteral nutrition, 39(Suppl. 1), 18S-32S. http://dx.doi.org/10.1177/0148607115595980. PMid:26177664.

Chang, N. W., \& Huang, P. C. (1998). Effects of the ratio of polyunsaturated and monounsaturated fatty acid to saturated fatty acid on rat plasma and liver lipid concentrations. Lipids, 33(5), 481-487. http://dx.doi. org/10.1007/s11745-998-0231-9. PMid:9625595.

Chen, F., Zhang, Q., Fei, S. M., Gu, H. Y., \& Yang, L. (2017). Optimization of ultrasonic circulating extraction of samara oil from Acer saccharum using combination of Plackett-Burman design and Box-Behnken design. Ultrasonics Sonochemistry, 35(Pt A), 161-175. http://dx.doi. org/10.1016/j.ultsonch.2016.09.015. PMid:27671519.

Chien, K. R., Bellary, A., Nicar, M., Mukherjee, A., \& Buja, L. M. (1983). Induction of a reversible cardiac lipidosis by a dietary long-chain fatty acid (erucic acid). Relationship to lipid accumulation in border zones of myocardial infarcts. American Journal of Pathology, 112(1), 68-77. PMid:6859230.

Flora of China Editorial Committee (2008). Flora of China (Vol. 11, p. 94). Beijing: Science Press and Missouri Botanical Garden Press. Retrieved from http://www.iplant.cn/info/Acer\%20triflorum?t=foc

Ge, Y., Chang, Y., Xu, W. L., Cui, C. S., \& Qu, S. P. (2015). Sequence variations in the FAD2 gene in seeded pumpkins. Genetics \& Molecular Research, 14(4), 17482-17488. http://dx.doi.org/10.4238/2015. December.21.19. PMid:26782391. 
Government of Canada (1978). Consolidated regulations of Canada, c.870, Food and Drugs Regulations. B.09.022. Canada.

$\mathrm{Hu}, \mathrm{P} ., \mathrm{Xu}, \mathrm{X} ., \mathrm{Y}$ \&u, L. L. (2017). Interesterified trans-free fats rich in sn-2 nervonic acid prepared using Acer truncatum oil, palm stearim and palm kernel oil, and their physicochemical propertise. Lebensmittel-Wissenschaft + Technologie, 76, 156-163. http://dx.doi. org/10.1016/j.lwt.2016.10.054.

Kramer, J. K. G., Sauer, F. D., Wolynetz, M. S., Farnworth, E. R., \& Johnston, K. M. (1992). Effects of dietary saturated fat on erucic acid induced myocardial lipidosis in rats. Lipids, 27(8), 619-623. http://dx.doi. org/10.1007/BF02536120. PMid:1383668.

Kumar, A., \& Sharma, S. (2011). Potential non-edible oil resources as biodiesel feedstocks: an Indian perspective. Renewable \& Sustainable Energy Reviews, 15(4), 1791-1800. http://dx.doi.org/10.1016/j. rser.2010.11.020.

Li, J. J., Fan, J. H., Wei, Y. C., \& Zhang, S. J. (2018). Analysis of nutrient composition of several kinds of Acer seeds oil. Journal of the Chinese Cereals and Oils Association, 33, 55-59.

Li, S. X., Wu, L., Li, Y. H., \& Yin, T. M. (2011). Study on water content in seed by low constant temperature oven method. Seed, 30, 72-74. http://dx.doi.org/10.16590/j.cnki.1001-4705.2011.05.043.

Liang, Q., Wang, W. W., Yuan, F. L., Liu, X., Li, D. L., \& Yang, K. Q. (2019). Characterization of yuanbaofeng (Acer truncatum Bunge) samaras: Oil, fatty acid, and phytosterol content. Industrial Crops and Products, 135, 344-351. http://dx.doi.org/10.1016/j.indcrop.2019.04.032.

Meesapyodsuk, D., Ye, S., Chen, Y., Chen, Y., Chapman, R. G., \& Qiu, $X$. (2018). An engineered oilseed crop produces oil enriched in two very long chain polyunsaturated fatty acids with potential health- promoting properties. Metabolic Engineering, 49, 192-200. http:// dx.doi.org/10.1016/j.ymben.2018.08.009. PMid:30149205.

Mersel, M., Heller, M., \& Pinson, A. (1979). Intracellular lipase activities in heart and skeletal muscle homogenates. The absence of trierucin cleavage by the heart: a possible biochemical basis for erucic acid lipidosis. Biochimica et Biophysica Acta, 572(2), 218-224. http:// dx.doi.org/10.1016/0005-2760(79)90037-7. PMid:427175.

Nelson, G. J. (1998). Dietary fat, trans fatty acids and risk of coronary heart disease. Nutrition Reviews, 6(8), 250-252. http://dx.doi. org/10.1111/j.1753-4887.1998.tb01758.x. PMid:9735680.

Qiao, Q., Ye, M. J., Si, F. F., Ren, H. J., An, K., Feng, Z., Zhang, L., \& Sun, Z. K. (2017). Variability of seed oil content and fatty acid composition in Shantung maple (Acer truncatum Bunge) germplasm for optimal biodiesel production. African Journal of Biotechnology, 16(48), 22322241. http://dx.doi.org/10.5897/AJB2017.16250.

Rabionet, M., Gorgas, K., \& Sandhoff, R. (2014). Ceramide synthesis in the epidermis. Biochimica et biophysica acta, 1841(3), 422-434. http://dx.doi.org/10.1016/j.bbalip.2013.08.011. PMid:23988654.

Schiefer, B., Loew, F. M., Laxdal, V., Prasad, K., Forsyth, G., Ackman, R. G., \& Olfert, E. D. (1978). Morphologic effects of dietary plant and animal lipids rich in docosenoic acids on heart and skeletal muscle of cynomolgus monkeys. American Journal of Pathology, 90(3), 551-564. PMid:415615.

Sissener, N.H., Ørnsrud, R., Sanden, M., Frøyland, L., Remø, S., \& Lundebye, A. K. (2018). Erucic Acid (22: $1 \mathrm{n}-9)$ in fish feed, farmed, and wild fish and seafood products. Nutrients, 10(10), 1443. http://dx.doi. org/10.3390/nu10101443. PMid:30301170. 